\title{
Factors Affecting Patients' Acceptance of and Satisfaction with Cloud-Based Telehealth for Chronic Disease Management: A Case Study in the Workplace
}

\author{
Yung-Yu Su, ${ }^{1, *}$ Su-Tsai Huang ${ }^{2, *} \quad$ Ying-Hsun $\mathrm{Wu}^{2}$ \\ ${ }^{1}$ Department of Long Term Care, National Quemoy University, \\ Kinmen, Taiwan \\ ${ }^{2}$ Department of Nursing, Changhua Christian Hospital, \\ Changhua, Taiwan \\ ${ }^{3}$ Research Education and Epidemiology Center, Changhua Christian \\ Hospital, Changhua, Taiwan
}

Appl Clin Inform 2020;11:286-294.

\author{
Chun-Min Chen ${ }^{3}$
}

\begin{abstract}
Objective Understanding patients' acceptance of and satisfaction with telehealth use is important for workplace health promotion. In this study, we used a questionnaire to measure patients' usage behavior and satisfaction with cloud-based telehealth services in the workplace. We empirically investigated the factors that influence patients' usage and satisfaction based on data collected from 101 participants.

Methods As its main research framework, this study utilized a revised version of the technology acceptance model 2 that was based on the telehealth services provided for chronic disease management. Through integrating a cross-sectional research design with an author-developed structured questionnaire that was assessed using reliability and validity tests, an anonymous survey was conducted on selected participants. The proposed research model and hypotheses were validated through path analysis using SPSS.

Results We found that users believe telehealth services can promote their workplace health management; that job relevance, result demonstrability, and perceived ease of use (PEOU) positively affect the perceived usefulness (PU), which implies that cognitive instrumental processes have the most significant impact on the PU of cloud-based telehealth; and that both PEOU and PU positively affect the intention to use (IU), but PU has a bigger influence than PEOU on users' intentions to continue using telehealth. In

Keywords

- satisfaction

- telehealth

- chronic disease management

- technology acceptance model 2 particular, the IU and actual usage behavior were critical to the patients' satisfaction with telehealth services.

Conclusion This research contributes to the rapid developing field of technology acceptance research by examining workplace telemedicine engagement. Our results will provide researchers with useful advice and a user-centered strategy for promoting workplace health management, which benefits both health care providers and corporate managers.
\end{abstract}

* These authors contributed equally to the work.

received

November 25, 2019

accepted

February 20, 2020 (c) 2020 Georg Thieme Verlag KG Stuttgart - New York
DOI https://doi.org/

10.1055/s-0040-1708838.

ISSN 1869-0327. 


\section{Background and Significance}

Telehealth is an assistive technology that has been used to mitigate the shortage of health care personnel and assist in the management of chronic diseases. Diabetes is a serious chronic condition that is recognized as an important cause of premature death and disability worldwide, ${ }^{1,2}$ and having metabolic syndrome drastically raises the risk of diabetes. ${ }^{3}$ Adequate glycemic control is essential in minimizing the long-term complications of prediabetes and diabetes. ${ }^{4}$ Self-management is an important skill for patients with diabetes mellitus, ${ }^{5,6}$ and this involves monitoring glucose levels and making behavioral changes to achieve better glycemic control. ${ }^{7}$ There is a large body of evidence that supports the use of innovative technologies, such as telehealth, to monitor and manage chronic diseases such as diabetes, orthopedic conditions, human immunodeficiency virus/acquired immunodeficiency syndrome, or renal disease at a distance and as frequently as necessary. ${ }^{4,8-13}$

Although there has been a high level of interest in using technology in health care and significant growth is expected in this area, ${ }^{14}$ implementation has not been without problems, and many of the forecasts have not yet been fully realized. ${ }^{15,16}$ For example, many telehealth services that started with pilot or small-scale projects are not regularly maintained, ${ }^{15,17,18}$ and telehealth is still not considered a mainstream activity in the health sector. ${ }^{15}$ It is estimated that up to $80 \%$ of technology projects introduced in the health care environment have failed. ${ }^{19}$ Faced with the rapid development and application of new technology, users' adoption and acceptance of each system and their satisfaction with using it are major issues worthy of attention.

Issues related to patient access and satisfaction are primary for many administrators. Theoretical frameworks for technology adoption can help elucidate possible user responses to new technological systems, as well as the drivers and barriers for subsequent adoption. Technology acceptance model (TAM) is one of the most widely used theories to study how users are motivated to adopt and use technology. ${ }^{20}$ Although the issue of user-centered design is important in the development of new technology, most studies focus on home- or hospital-based telehealth care, ${ }^{21-23}$ and no one has explicitly considered the possibility of integrating workplace health management to move beyond the home and hospital settings. Therefore, this study adopted TAM $2^{24}$ as the main research framework, and revised it to use for evaluating telehealth services in the workplace.

\section{Objectives}

The objective of this study was to evaluate patients' acceptance of and satisfaction with using cloud-based telehealth services in the workplace to support their practical needs and self-care behavior for health management.

\section{Methods}

\section{The Cloud-Based Telehealth Service}

As part of workplace health promotion, a medical center and an enterprise began utilizing smart technology to allow employees to conduct self-health management beginning in 2017. This telehealth cloud is a Web-based system accessible on the Internet and is, therefore, not limited to operating systems or devices. The telehealth platform provides a comprehensive health solution that includes hardware, software, and services. The hardware is a Bluetooth-connected wireless measuring device, the software is a Web-based platform with the application (APP), and the service is a medical institution that provides services related to chronic disease care and health promotion.

The health care cloud management platform provides telehealth care to employees, collects physiological data through wireless health measurement medical equipment and wearable devices, and provides health monitoring and telehealth care services for employees with chronic diseases. Health monitoring is mainly used to assist with the daily management of self-health. Users can use measurement devices such as blood pressure monitors, blood glucose meters, and smart wearables to monitor their own physiological measurement values, which can be continuously recorded and observed. Data can also be sent via the cloud-based health platform for collection and analysis by the professional team. If abnormal signs are detected, the remote smart device can be used to provide appropriate advice or information to patients immediately. - Fig. 1 shows the infrastructure design of the online health care management system (Telehealth care).

\section{Participant Recruitment}

In this study, a purposive sampling approach was used to collect the data. A cross-sectional research design with a questionnaire-base survey was implemented to collect data for assessing participant (employees with chronic disease) perceptions regarding the telehealth system. The research

\section{Telehealth care process}

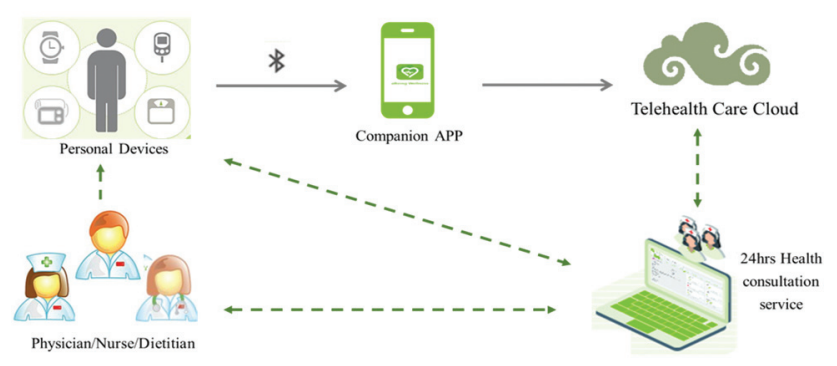

Fig. 1 Designing of the online diabetes health care management system. The caregiver can collect physiological data through wireless health measurement medical equipment and wearable devices, and send data and data analysis through the health platform to the professional team through the telehealth cloud; caregivers can also access the system and provide information and support to ensure interoperability between systems (Source: Telehealth Counseling Center of the Medical Center). 
team offered onsite explanations of the study and the questionnaire survey was distributed in the company health center after employees had completed their clinical check. Inclusion criteria were as follows: (1) metabolic syndrome ( $\geqq 3$ items): body mass index $\geqq 24$; systolic blood pressure $\geqq 140 \mathrm{~mm} \mathrm{Hg}$; diastolic blood pressure $\geqq 90 \mathrm{~mm} \mathrm{Hg}$; fasting blood glucose $\geqq 101 \mathrm{mg} / \mathrm{dL}$; hemoglobin A1c $\geqq 7 \%$; triglyceride $\geqq 150 \mathrm{mg} / \mathrm{dL} ;$ low-density lipoprotein cholesterol $\geqq 130 \mathrm{mg} / \mathrm{dL}$. ( 2 ) Diabetes ( $\geqq 1$ item): fasting blood glucose $\geqq 126 \mathrm{mg} / \mathrm{dL}$; random blood glucose $\geqq 200 \mathrm{mg} / \mathrm{dL}$; polydipsia; polyuria; polyphagia; weight loss. Employees who met either criteria (metabolic syndrome $\geqq 3$ items or diabetes $\geqq 1$ item) were included in the study. Exclusion criteria were (1) unwillingness to participate after being fully informed, (2) involuntary use of the system, and (3) less than 3 months of use. A copy of the research instructions was attached to each questionnaire to achieve informed consent, allowing participants to comprehend the research objectives before answering the questionnaire. In total, 200 questionnaires were distributed, and after deleting 3 invalid questionnaires, which were not fully completed, the final sample contained 101 completed surveys that were collected by postal response. The survey was conducted between October 2017 and January 2018. It was conducted with the approval of the Human Research Protection Program of Changhua Christian Hospital (Institutional Review Board No. 160819) and abided by the principles of beneficence, autonomy, and equality during data collection.

\section{Research Design and Framework}

Technology acceptance is a key factor affecting the adoption of a new system. Despite the continuous development and diversification of telehealth technology, there is still an urgent need to investigate the acceptance and satisfaction of new technologies by end-users to assist patients with chronic diseases to perform good health management. The primary purpose of this research was to develop a conceptual model to predict the acceptance of and satisfaction with telehealth in the workplace. Telehealth is a Web-based information system that exhibits information technology characteristics. Therefore, it is reasonable to construct a research model based on technology acceptance theories, such as $\mathrm{TAM}^{25}$ which can explain $60 \%$ of technology acceptance. ${ }^{26}$ Therefore, this study adopted and extended TAM2 ${ }^{24}$ to acquire participants' detailed opinions about their acceptance of and satisfaction with telehealth and explore significant factors behind endusers' responses to this program. ${ }^{24,27}$ The conceptual framework is shown in = Fig. 2.

A quantitative method based on a TAM questionnaire was designed as the main research tool. - Table 1 provides detailed conceptual definitions of the main dimensions and evaluation indicators of the questionnaire. The questionnaire had 12 dimensions in total with 75 items, and a 5-point Likert scale, ranging from strongly disagree (score: 1) to strongly agree (score: 5), was employed as the evaluation method. After the validity (Cronbach's $\alpha>0.8$, corrected item total correlations $>0.35$ ) and reliability (communality $>0.4$, factor loadings $>0.4$, Kaiser-MeyerOlkin value $>0.6$ ) assessment of the measurement model, the structural model was examined to test the hypotheses proposed for conceptual modeling in this study.

\section{Research Hypotheses}

TAM theorizes that perceived usefulness (PU) and perceived ease of use (PEOU) are antecedents to attitudes toward the adoption of a technology and that they are determined by external factors. According to Davis et al, ${ }^{25}$ "PU" is defined as the degree to which a person believes that using a particular system would enhance his or her job performance, whereas "PEOU" is defined as the degree to which a person believes

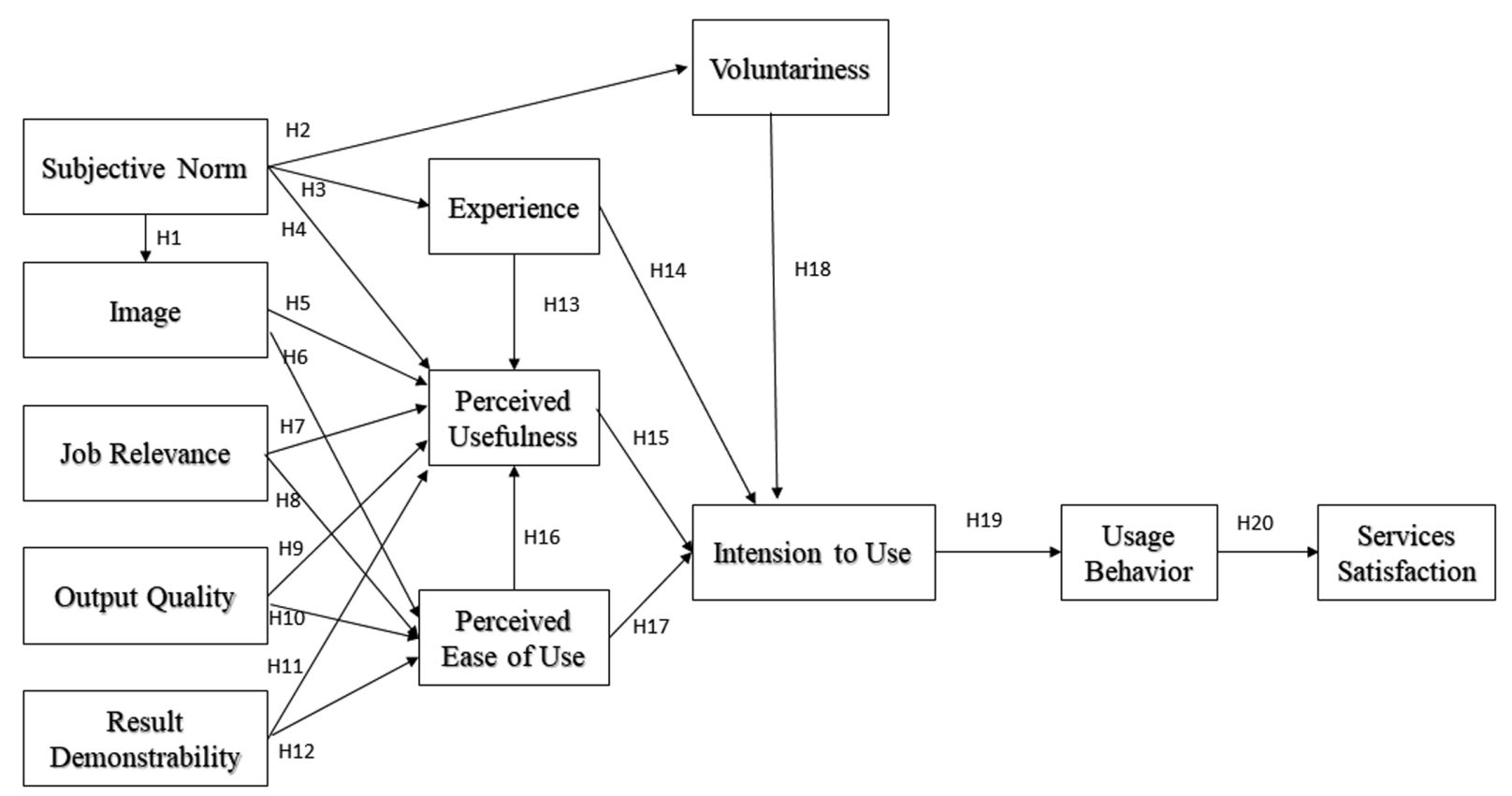

Fig. 2 Research design and procedure of the framework. 
Table 1 Evaluation dimensions, conceptual definitions, and indicators

\begin{tabular}{|c|c|c|}
\hline $\begin{array}{l}\text { Evaluation } \\
\text { dimensions }\end{array}$ & Conceptual definitions & Evaluation Indicators \\
\hline $\begin{array}{l}\text { Subjective } \\
\text { norm }\end{array}$ & $\begin{array}{l}\text { Users' perceived pressure or push factors when using } \\
\text { telehealth }\end{array}$ & $\begin{array}{l}\text { Recommend to use by others, encourage to use by } \\
\text { others, continuous use }\end{array}$ \\
\hline Image & $\begin{array}{l}\text { The degree to which use of telehealth is perceived to } \\
\text { enhance health image of users }\end{array}$ & $\begin{array}{l}\text { Personal image, health control, health awareness, care } \\
\text { service }\end{array}$ \\
\hline Job relevance & $\begin{array}{l}\text { A user's perception regarding the degree to which the } \\
\text { telehealth is applicable to manage their health }\end{array}$ & $\begin{array}{l}\text { Rewarding, system functions, system services, gain } \\
\text { knowledge, effectiveness }\end{array}$ \\
\hline Output quality & $\begin{array}{l}\text { Perceived quality of tasks fulfilled by means of the } \\
\text { telehealth }\end{array}$ & $\begin{array}{l}\text { Accurate data, quality, meet the requirement, easy to } \\
\text { understand }\end{array}$ \\
\hline $\begin{array}{l}\text { Result } \\
\text { demonstrability }\end{array}$ & $\begin{array}{l}\text { The degree to which the results or benefits of using the } \\
\text { telehealth are apparent }\end{array}$ & $\begin{array}{l}\text { Online stability, easy interpretation, system } \\
\text { advantages, interactive, easy to use }\end{array}$ \\
\hline $\begin{array}{l}\text { Perceived } \\
\text { usefulness }\end{array}$ & $\begin{array}{l}\text { The degree to which a person believes that using } \\
\text { telehealth would enhance his or her health status }\end{array}$ & $\begin{array}{l}\text { Understanding, assist, effectiveness, real-time, } \\
\text { receiving information, complete record, share in time, } \\
\text { easy to share, Interactive process, system service }\end{array}$ \\
\hline $\begin{array}{l}\text { Perceived } \\
\text { ease of use }\end{array}$ & Users' perceived easiness to use telehealth & $\begin{array}{l}\text { Ease to learn, ease to use, ease of use, clear and } \\
\text { understandable, ease to access, ease to operate }\end{array}$ \\
\hline Intention to use & $\begin{array}{l}\text { Users' subjective intention toward Telehealth use in the } \\
\text { future }\end{array}$ & $\begin{array}{l}\text { Continue to use, recommend for others, priority use, } \\
\text { share information, interactive, attempt to use }\end{array}$ \\
\hline Usage behavior & Users' experience with telehealth after actual use & $\begin{array}{l}\text { Usage time, usage frequency, interaction, effectiveness } \\
\text { of daily use }\end{array}$ \\
\hline Experience & User's personal experience with telehealth use & $\begin{array}{l}\text { Health status, diet, system service, exercise, } \\
\text { explanation, self-care, standard criteria, problem solved }\end{array}$ \\
\hline Voluntariness & Users' willingness to continue using telehealth & $\begin{array}{l}\text { Initiative to try, seeking information, recommend for } \\
\text { others, sharing information, setting standards, service } \\
\text { improvement }\end{array}$ \\
\hline $\begin{array}{l}\text { Services } \\
\text { satisfaction }\end{array}$ & User satisfaction with telehealth use & $\begin{array}{l}\text { Education, care service, professional knowledge, } \\
\text { timeless, technical support assistance, remote } \\
\text { assistance, troubleshoot, hardware equipment, system } \\
\text { functions, cost, consultation service }\end{array}$ \\
\hline
\end{tabular}

that using a particular system would be free from effort. ${ }^{24}$ In this regard, this study hypothesizes that

H 15: PU will have a positive effect on intention to use (IU). $\mathrm{H}$ 16: PEOU will have a positive effect on PU.

$\mathrm{H}$ 17: PEOU will have a positive effect on IU.

Subsequently, TAM2 ${ }^{24}$ extended the $\mathrm{TAM}^{25}$ to reflect social influence (subjective norms, voluntariness, and image) and cognitive instrumental processes (job relevance [JR], output quality [OQ], result demonstrability [RD], and PEOU). Therefore, it is hypothesized that

$H$ 1: Subjective norm (SN) will have a positive effect on image.

$\mathrm{H}$ 2: SN will have a positive effect on voluntariness (VOL).

$\mathrm{H}$ 3: SN will have a positive effect on experience.

$\mathrm{H}$ 4: SN will have a positive effect on PU.

H 5: Image will have a positive effect on PU.

H 7: JR will have a positive effect on PU.

H 9: OQ will have a positive effect on PU.

$\mathrm{H}$ 11: RD will have a positive effect on PU.

$H$ 13: Experience (EXP) will have a positive effect on PU.

$H$ 14: EXP will have a positive effect on IU.

$\mathrm{H}$ 18: VOL will have a positive effect on IU.

$\mathrm{H}$ 19: IU will have a positive effect on usage behavior (UB).
Throughout the evolution of different TAM models, PEOU and PU have been shown to be closely related, so we can assume that the factors that affect PU will also affect PEOU. Therefore, we assume that PEOU is correlated with image, JR, $\mathrm{OQ}$, and RD, which are direct determinants of PU. We believe that the less effort required to use a system, the more likely it is that using it can improve a patient's ability to manage chronic diseases through self-care.

H 6: Image will have a positive effect on PEOU.

$\mathrm{H}$ 8: JR will have a positive effect on PEOU.

$\mathrm{H}$ 10: OQ will have a positive effect on PEOU.

$\mathrm{H}$ 12: RD will have a positive effect on PEOU.

With the increasing prevalence of telehealth, it is important to maintain the key quality indicator of patient satisfaction. Empirical evidence has demonstrated that system UB is linked with user satisfaction. ${ }^{28}$ Therefore, it is possible to use these measures to benchmark user satisfaction in terms of service use.

H 20: UB will have a positive effect on services satisfaction (SS).

\section{Data Analysis}

To characterize the sample, descriptive analyses (number and percentage) using demographic data were conducted. 
The mean test was used to calculate the satisfaction score for each dimension. To examine the associations among each dimension, the path model was explored based on structural equation modeling (SEM). Path analysis (PA) is an extension of multiple regression, which identifies effects between variables in a proposed model. ${ }^{29-31}$ Using PA, direct and indirect effects were tested, and the strength of the effects was quantified by calculating the standardized regression coefficient $(\beta)$. This $\beta$ weight allowed for an interpretation of the strength of the effects between the variables. While the interpretation does not imply causality, it does have the power to predict relationships. The model fit was evaluated using several indices: the goodness-of-fit (GFI), the comparative fit index (CFI), the incremental fit index (IFI), the normed fit index (NFI), and the root means square error of approximation (RMSEA). Values of GFI $\geqq 0.90$, CFI $\geqq 0.90$, IFI $\geqq 0.90$, NFI $\geqq 0.90$, and RMSEA $<0.08$ are assumed to be indicative of a good-fitting model, as recommended by $\mathrm{Hu}$ and Bentler ${ }^{32}$ and McDonald and Ho. ${ }^{33}$ IBM SPSS Statistics for Windows and AMOS, version 22.0 (IBM Corporation, Armonk, New York, United States) was used to analyze the results. The level of significance was set at $p<0.05$.

\section{Research Results}

\section{Demographic Variables}

We collected survey data, and 101 participants, who each had participated in the telehealth program for at least 3 months, were selected for analysis. There were 76 (75.2\%) male respondents, but we found that gender differences had no effect on any of the variables examined. In addition, 65 respondents (64.4\%) lived in central Taiwan, 22 respondents (21.8\%) lived in northern Taiwan, and 14 respondents (13.9\%) lived in Taipei City. Details of the demographic variables are shown in -Table 2.

\section{Mean Satisfaction Score for Each Dimension}

The average user evaluation score was 4.50 , which indicates a medium level of satisfaction. As shown in - Table 3, the mean SN and VOL scores were 3.83 and 3.98, respectively, signifying that users only agree (rather than strongly agree) with these two dimensions. The fact that the remaining dimensions all received a mean score exceeding 4 shows that users thought telehealth service was able to meet the requirements of workplace health management.

\section{Results of TAM Evaluation}

A summary of the PA model is presented in -Fig. 3. A goodness-of-fit test was performed, yielding results that met relevant requirements: ${ }^{2} / \mathrm{df}=1.271(\leq 3), \mathrm{GFI}=0.94$ ( $\geq 0.90), \mathrm{CFI}=0.99(\geq 0.90), \mathrm{NFI}=0.96(\geq 0.90), \mathrm{IFI}=0.99$ $(\geq 0.90)$, and RMSEA $=0.05$ ( $<0.08)$. Our findings validated 12 hypotheses and rejected 8 among all 20 hypotheses that were proposed based on the research framework. Therefore, the following conclusions were made: (1) SN positively affected image, EXP, and VOL, with coefficients of 0.27 , 0.57 , and 1.47 ( $\mathrm{H} 1, \mathrm{H} 2$, and $\mathrm{H} 3$ ), respectively; (2) JR positively affected PU and PEOU, with coefficients of 0.39 and 0.51 (H7 and $\mathrm{H} 8$ ), which demonstrates that JR has a larger effect on
Table 2 The demographic variables of participants $(n=101)$

\begin{tabular}{|c|c|c|c|}
\hline \multicolumn{2}{|r|}{ Variables } & $N$ & $(\%)$ \\
\hline \multirow[t]{2}{*}{ Sex } & Male & 76 & 75.2 \\
\hline & Female & 25 & 24.8 \\
\hline \multirow[t]{6}{*}{ Age } & $30-34$ years old & 9 & 8.9 \\
\hline & $35-39$ years old & 31 & 30.7 \\
\hline & 40-44 years old & 28 & 27.7 \\
\hline & 45-49 years old & 17 & 16.8 \\
\hline & $50-54$ years old & 9 & 8.9 \\
\hline & 55-59 years old & 7 & 6.9 \\
\hline \multirow{4}{*}{$\begin{array}{l}\text { Educational } \\
\text { attainment }\end{array}$} & Senior high school & 11 & 10.9 \\
\hline & Junior college & 16 & 15.8 \\
\hline & Bachelor & 35 & 34.7 \\
\hline & Postgraduate school & 39 & 38.6 \\
\hline \multirow[t]{4}{*}{ Occupation } & Electronic industry & 48 & 47.5 \\
\hline & Manufacturing industries & 26 & 25.7 \\
\hline & $\begin{array}{l}\text { Information and } \\
\text { communications industry }\end{array}$ & 23 & 22.8 \\
\hline & Others & 4 & 4.0 \\
\hline \multirow{2}{*}{$\begin{array}{l}\text { Length } \\
\text { of use }\end{array}$} & $3 \mathrm{mo}$ & 97 & 96.0 \\
\hline & $\begin{array}{l}\text { Less than } 6 \mathrm{mo} \\
\text { (including } 6 \mathrm{mo} \text { ) }\end{array}$ & 4 & 4.0 \\
\hline \multirow{3}{*}{$\begin{array}{l}\text { Place of } \\
\text { residence }\end{array}$} & Central Taiwan & 65 & 64.4 \\
\hline & Taipei City & 14 & 13.9 \\
\hline & Northern Taiwan & 22 & 21.8 \\
\hline
\end{tabular}

PEOU; (3) RD positively affected PU and PEOU, with coefficients of 0.35 and 0.37 (H11 and H12); (4) PEOU positively affected PU, with the coefficient of 0.21 (H16); (5) PU and PEOU positively affect IU, with coefficients of 0.74 and 0.21 (H15 and H17), which means that PU has a larger influence than PEOU on patients' intentions to use telehealth; (6) IU positively affected UB, with a coefficient of 0.97 (H19); and (7) UB positively affected SS (H20), with a coefficient of 0.98 . The results indicate that the most important factors that influence patients' intentions of using telehealth are JR and RD. This study indicated that there was a positive linear relationship between system satisfaction and acceptance.

\section{Application of TAM2 for Patients in the Workplace}

Most of the participants were approximately 35 to 44 years old and were highly educated. Their occupations are related to technology, so they are familiar with operating devices (SN) such as mobile phones and tablets, and they have APP experience (EXP). These experiences also strengthen their willingness to use a new technology like telehealth (VOL). New cloud-based telehealth services were introduced into the workplace, and because these were not limited to the home or hospital settings, they make self-control and health management of diseases easier (PEOU). Through regular physiological monitoring and data analysis, personalized health advice can be provided (JR), and patients with abnormal physiological values can be 
Table 3 The values of Mean of satisfaction score for each dimension

\begin{tabular}{|l|l|l|l|l|l|l|l|l|l|l|l|l|}
\hline \multirow{2}{*}{ Questions } & \multicolumn{10}{|c|}{ Evaluation dimensions } \\
\cline { 2 - 13 } & A & B & C & D & E & F & G & H & I & J & K & L \\
\hline 1 & 4.24 & 4.16 & 4.42 & 4.27 & 3.95 & 4.33 & 4.22 & 4.00 & 4.15 & 4.33 & 4.05 & 4.29 \\
\hline 2 & 4.09 & 4.23 & 4.46 & 4.20 & 4.19 & 4.27 & 4.20 & 4.17 & 4.19 & 4.26 & 3.88 & 4.33 \\
\hline 3 & 3.72 & 4.19 & 4.36 & 4.22 & 4.11 & 4.29 & 3.92 & 4.07 & 4.04 & 4.20 & 3.97 & 4.34 \\
\hline 4 & 3.66 & & 4.28 & & 4.03 & 4.21 & 4.15 & 4.01 & 4.07 & 4.19 & 3.95 & 4.28 \\
\hline 5 & 3.42 & & 4.29 & & & 4.21 & 4.30 & 4.02 & 4.16 & 4.28 & 4.09 & 4.21 \\
\hline 6 & & & & & & 4.34 & 4.28 & 4.14 & 4.12 & 4.30 & 3.91 & 4.13 \\
\hline 7 & & & & & & 4.32 & & & & 4.16 & & 4.13 \\
\hline 8 & & & & & & 4.28 & & & & 4.04 & & 4.24 \\
\hline 9 & & & & & & 4.25 & & & & & & 4.19 \\
\hline 10 & & & & & & 4.26 & & & & & & 4.23 \\
\hline 11 & & & & & & & & & & & & 4.29 \\
\hline 12 & & & & & & & & & & & & \\
\hline 13 & 3.83 & 4.19 & 4.36 & 4.23 & 4.07 & 4.27 & 4.18 & 4.07 & 4.12 & 4.22 & 3.98 & 4.22 \\
\hline Mean & & & & & & & & & & 4.19 \\
\hline
\end{tabular}

Note: A: Subjective Norm; B: Image; C: Job Relevance; D: Output Quality; E: Result Demonstrability; F: Perceived Usefulness; G: Perceived Ease of Use; $\mathrm{H}$ : Intension to Use; I: Usage Behavior; J: Experience; K: Voluntariness; L: Services Satisfaction.

Boldfaced values denote scores below average.

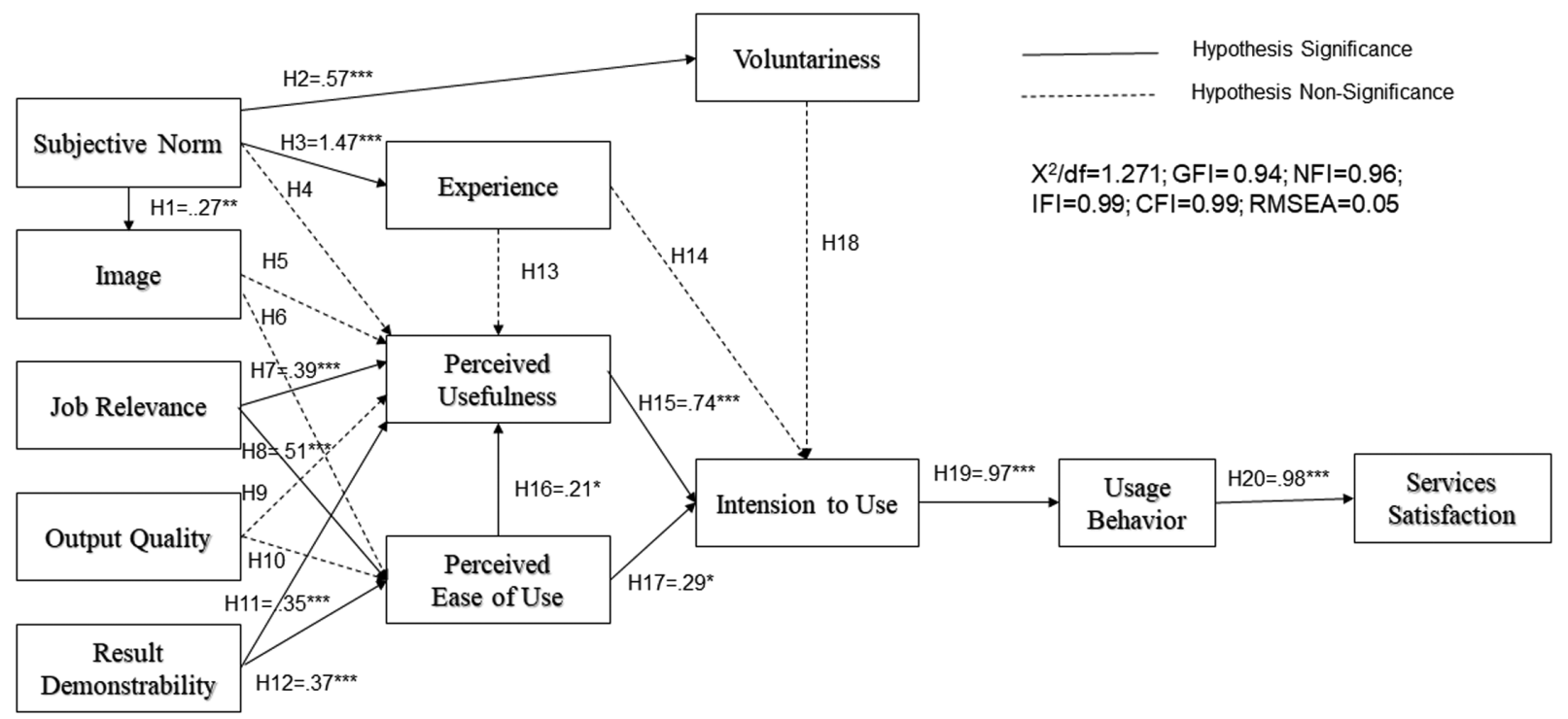

Fig. 3 Results of testing the research model. The numerical figure is standardized parameter estimate, ${ }^{*} p$-value $<0.05 ;{ }^{* *} p$-value $<0.01 ;{ }^{* * *} p$-value $<0.001$.

notified immediately (RD). This may help individuals better understand their own health and improve their effectiveness in caring for chronic diseases (PU), so that patients are more willing to use (IU) and cooperate with telehealth care plans (UB), and this may ultimately improve their satisfaction with the system (SS). Overall, we discovered that telehealth could meet the health management needs of employees with chronic diseases in the workplace.

\section{Discussion}

This study provides empirical support for the hypotheses proposed in relation to PU, PEOU, RD, and JB in the system usage, all of which have an impact on system acceptance and satisfaction. In addition, the results of this study demonstrated that JB and RD not only affected PU and PEOU simultaneously, but also had a relatively strong influence on PEOU. Specifically, PU and PEOU were critical factors associated with patients' actual and continued use of the system. Finally, there was a positive linear relationship between SS and UB.

In contrast to previous research, ${ }^{24}$ the $\mathrm{SN}-\mathrm{IU}$ relationship was not moderated by "EXP" and VOL (H14 and H18). TAM2 theorizes that the direct impact of SN on users' intentions to use the system will be strong initially, but will weaken over time as increasing direct experience with the system provides a better basis for IU it on an ongoing basis. ${ }^{24}$ This idea was 
supported by this study because all users were voluntarily paying to use the telehealth system, which they used for more than 3 months. Furthermore, the SN-PU relationship was not moderated by EXP (not supporting H13). Although the hypothesis that SN affected image (H1) was supported by TAM2, the image-PU relationship was not (H5). In this study, the hypotheses related to the relationship between social influences (EXP, VOL, SN, and image) and the "IU" in the workplace system were rejected.

In addition, the positive influence of cognitive instrumental processes, including JR, RD, and PEOU on PU and IU in the system was empirically confirmed. First, JR relates to the personal perception of whether the use of the telehealth system can effectively support work tasks. This study supported the hypothesis that not only is JR an important factor that determines whether medical professionals in medical institutions will accept the telehealth system, ${ }^{34}$ but it is also helpful for improving the health care of patients in the workplace. When using the telehealth system allows a user to simultaneously maintain his or her health and meet job needs (JR), PEOU and PU will increase because users believe that good health management will help them work better.

Second, RD makes it easy for others to recognize the positive effects of technology use, so the use of technology can improve PEOU and PU. The effect of the RD factor on patients' intentions to use the system may be due to the tangible improvements in patient care that result from using telehealth in the workplace. For example, personal health data can be sent to medical institutions via the telehealth care cloud where caregivers can then review abnormal cases in a timely manner and provide proactive services to assist with early warning and further reduce the risks of chronic disease.

Furthermore, the greater the PU and PEOU, the greater a patient's intentions (IU) and actual use (UB), which was demonstrated by Davis et al. ${ }^{25}$ Our study supports these findings and suggests that patients with chronic diseases adopt APP with adequate support. They will ultimately perceive that they are able to improve their self-care behaviors, thereby leading to better health. We found that telehealth has been demonstrated to play a positive role in the workplace-based treatment of chronic diseases such as diabetes ${ }^{35}$ and other diseases. ${ }^{10}$ Mettler revealed that automatic behavior or habits can facilitate electronic medical record adoption. ${ }^{36}$ Because participants possessed the APP and monitors, they knew their blood glucose and blood pressure values instantly, which helped them to control their diet and increased their attention to personal health. This implies that users believed that using telehealth increased their ability to efficiently manage their health, which in turn contributes to better control of chronic diseases and supports work health promotion.

Finally, we also extended TAM2 to determine if the system's UB positively affected SS. Using data and explicit satisfaction feedback collected from this study, it was found that user behavior is closely related to satisfaction. The average score for overall satisfaction with the telehealth care system was 4.2 (median score: 4.0). It has been reported that users (patients) in general are satisfied with such telehealth services and believe that using them can lead to improvements in their health. ${ }^{37}$ As health awareness has increased in recent years, consumers have also begun using wearables devices and medical mobile apps to manage their medical records, nutrition, medications, and other information. Therefore, user satisfaction can be predicted by examining UB, because it indicates that the participants who actually repeatedly use the telehealth system find it to be effective. Because the behavior of patients can be affected by their intentions, to effectively predict user satisfaction, one needs to consider not only the actual use but also the underlying intent of each user with respect to their experiences. As a result, system providers who understand how consumers use digital technology and take action can develop better patient engagement strategies and help individuals make better health management.

The aging and declining births have caused a serious shortage of care manpower, so the development of telehealth applications has become the common goal of many countries. Due to the spread of medical information and the development of science and technology, patients' requirements for medical care are also different from before. According to Internet World Stats statistics 2019, ${ }^{38}$ Taiwan 's Internet users in June 2019 reached 92.8\%, compared with 89.4\% in North America, 39.6\% in Africa, $87.7 \%$ in Europe, 68.9\% in Latin America, and 68.4\% in Australia, therefore, Taiwan can be regarded as the best field for cloud-based telehealth application. The workplace is an important setting for health promotion and disease prevention programs. On average, Taiwanese who are working fulltime spend more than one-third of their day, 5 days per week, at the workplace. As discussed in other studies, ${ }^{37}$ the high user acceptance rate of telehealth systems means that telehealth can facilitate the monitoring of chronic diseases. Furthermore, high user satisfaction indicates that telehealth services are suitable for use in workplace health management. Unlike early telehealth, which only connected hospital and home, ${ }^{13,22}$ this cloud-based telehealth platform can provide care at multiple locations, connecting community-based health care providers and patients across the lifecycle of care delivery-in the workplace, hospital, and at home.

This study had several limitations. First, it was a crosssectional study that utilized a small sample, with participants selected from two technology companies and without a control group from the community or hospital. This could weaken the interpretation of the results. Because the telehealth care cloud was only implemented recently, end-users had a relatively low willingness to participate in the research. Future studies could collect physiological data at different time periods and evaluate the results by conducting repeated-measure analyses or control-group selection to verify the effects of this care on chronic disease management. Moreover, further studies could evaluate whether such a system is successful at promoting self-management in patients with chronic diseases. Although postal surveys are commonly used to gather information from health care research, mean response rates to postal surveys are low $(42-56 \%)^{39,40}$; this was also true in this study (51\%). This could result in unknown levels of bias (nonresponse bias). A sample size of 100 to 200 is generally considered to be the minimum sample size for conducting SEM. ${ }^{41}$ Although a notable limitation of TAM-based studies is self-reported, actual usage, that is, 
UB driven by IU, is usually surrogated by a person's selfreported usage. This is still the most straightforward way to understand the end-user's perception of accepting a new technology based on quantitative research strategy.

\section{Conclusion}

This study contributed to evaluating the adoption of telehealth by applying revised TAM2. It indicated that cognitive tool processes are more important than social impact processes among people who are using telehealth in the workplace. During implementation and use of the system, changes in user behavior are critical to the ultimate success of the system, and these behaviors can also predict user satisfaction with the system. If the behavior is inconsistent with the usage of the system, it may lead to low system acceptance and satisfaction. These findings provide valuable information that telehealth service providers, workplace supervisors, and health care providers can use to improve strategies and accelerate adoption of the technology. By understanding how telehealth can be accepted by its users for managing their health, the needs of users can be accurately presented, and the gap between service providers and those in need can be reduced. The next step in the research plan is to consider the success of cloud-based telehealth care in workplace health management using a larger sample size.

\section{Clinical Relevance Statement}

This study enhances our understanding of the acceptance of and satisfaction with cloud-based telehealth care for workplace health management from the perspective of patients. It provides valuable evidence that telehealth service system developers and care personnel can use to overcome deficiencies in the existing telehealth systems to maintain patients' loyalty and allow for the successful implementation of telehealth in the future.

\section{Multiple Choice Questions}

1. What kind of the effectiveness care has been widely adopted in diabetes care and metabolic control?
a. Telehealth care.
b. Intensive care.
c. Health care.
d. Long term care.

Correct Answer: The correct answer is option a. The effectiveness of telehealth care has been indicated and online informatics applications have been widely adopted in diabetes care and metabolic control.

2. For health information system evaluation, what is the most appropriate model for recognizing end-users' opinion of rejection or acceptance health care technology?

a. Information success model (IS success model).

b. Technology acceptance model II (TAM II).

c. Technology task fit model (TTF model). d. Social technology model.

Correct Answer: The correct answer is option b. The initial version of the TAM II was designed to determine behaviors of computer system users, exploring significant factors behind end-users' responses to information systems (i.e., rejection or acceptance technology).

3. What are the benefits of receiving telehealth for diabetes care?

a. Self-monitoring blood glucose to strengthen self-care.

b. Promote the quality of insulin injection care.

c. Behavior improvement (diet / exercise / medication).

d. All of the above.

Correct Answer: The correct answer is option d. Telehealth for diabetes provides for tighter glucose control, improved clinical outcomes, and behavior change that prevents or arrests development of serious complications.

4. In which areas can the cloud-based health management platform be used for chronic disease management?

a. Home.

b. Hospital.

c. Workplace.

d. All of the above.

Correct Answer: The correct answer is option d. This cloud-based telehealth platform can provide care at multiple locations, connecting community-based health care providers and patients across the lifecycle of care delivery -in the workplace, hospital, and at home.

\section{Protection of Human and Animal Subjects}

The study was performed in compliance with the World Medical Association Declaration of Helsinki on Ethical Principles for Medical Research Involving Human Subjects, and was reviewed by Human Research Protection Program of Changhua Christian Hospital (Institutional Review Board No. 160819).

\section{Funding}

This work was founded in part by a grant from the Changhua Christian Hospital (105-CCH-IRP-150).

Conflict of Interest

None declared.

\section{Acknowledgments}

The authors thank the staffs from Changhua Christian Hospital who helped to complete the task of data collection that greatly assisted the research.

\section{References}

1 Baena-Díez JM, Peñafiel J, Subirana I, et al; FRESCO Investigators. Risk of cause-specific death in individuals with diabetes: a competing risks analysis. Diabetes Care 2016;39(11):1987-1995

2 Wong E, Backholer K, Gearon E, et al. Diabetes and risk of physical disability in adults: a systematic review and meta-analysis. Lancet Diabetes Endocrinol 2013;1(02):106-114 
3 Shin JA, Lee JH, Lim SY, et al. Metabolic syndrome as a predictor of type 2 diabetes, and its clinical interpretations and usefulness. J Diabetes Investig 2013;4(04):334-343

4 Davis RM, Hitch AD, Salaam MM, Herman WH, Zimmer-Galler IE, Mayer-Davis EJ. TeleHealth improves diabetes self-management in an underserved community: diabetes TeleCare. Diabetes Care 2010;33(08):1712-1717

5 Glasgow RE, Christiansen SM, Kurz D, et al. Engagement in a diabetes self-management website: usage patterns and generalizability of program use. J Med Internet Res 2011;13(01):e9

6 Lin YH, Chen RR, Guo SH, Chang HY, Chang HK. Developing a web 2.0 diabetes care support system with evaluation from care provider perspectives. J Med Syst 2012;36(04):2085-2095

7 Kebede MM, Schuett C, Pischke CR. The role of continuous glucose monitoring, diabetes smartphone applications, and self-care behavior in glycemic control: results of a multi-national online survey. J Clin Med 2019;8(01):E109

8 Hanlon P, Daines L, Campbell C, McKinstry B, Weller D, Pinnock H. Telehealth interventions to support self-management of longterm conditions: a systematic metareview of diabetes, heart failure, asthma, chronic obstructive pulmonary disease, and cancer. J Med Internet Res 2017;19(05):e172-e172

$9 \mathrm{Wu} \mathrm{C}, \mathrm{Wu}$ Z, Yang L, et al. Evaluation of the clinical outcomes of telehealth for managing diabetes: a PRISMA-compliant metaanalysis. Medicine (Baltimore) 2018;97(43):e12962

10 Cho H, Iribarren S, Schnall R. Technology-mediated interventions and quality of life for persons living with HIV/AIDS. A systematic review. Appl Clin Inform 2017;8(02):348-368

11 Datillo JR, Gittings DJ, Sloan M, Hardaker WM, Deasey MJ, Sheth NP. "Is There An App For That?" Orthopaedic patient preferences for a smartphone application Appl Clin Inform 2017;8(03):832-844

12 Quintana Y, Gonzalez Martorell EA, Fahy D, Safran C. A systematic review on promoting adherence to antiretroviral therapy in HIVinfected patients using mobile phone technology. Appl Clin Inform 2018;9(02):450-466

13 Magnus M, Sikka N, Cherian T, Lew SQ. Satisfaction and improvements in peritoneal dialysis outcomes associated with telehealth. Appl Clin Inform 2017;8(01):214-225

14 Wong AMK, Chang W-H, Ke P-C, et al. Technology acceptance for an Intelligent Comprehensive Interactive Care (ICIC) system for care of the elderly: a survey-questionnaire study. PLoS One 2012; 7(08):e40591-e40591

15 Standing C, Standing S, McDermott M-L, Gururajan R, Kiani Mavi R. The paradoxes of telehealth: a review of the literature 2000-2015. Syst Res Behav Sci 2018;35(01):90-101

16 Zanaboni P, Wootton R. Adoption of telemedicine: from pilot stage to routine delivery. BMC Med Inform Decis Mak 2012;12:1

17 Wade VA, Eliott JA, Hiller JE. Clinician acceptance is the key factor for sustainable telehealth services. Qual Health Res 2014;24(05): 682-694

18 Greenhalgh T, Wherton J, Papoutsi C, et al. Beyond adoption: a new framework for theorizing and evaluating nonadoption, abandonment, and challenges to the scale-up, spread, and sustainability of health and care technologies. J Med Internet Res 2017;19(11):e367

19 Greenhalgh T. How to Implement Evidence-Based Healthcare. Hoboken, NJ, USA: Wiley Blackwell; 2018

20 Venkatesh V, Bala $\mathrm{H}$. Technology acceptance model 3 and a research agenda on interventions. Decis Sci 2008; 39(2): 273-315

21 Rudin RS, Fanta CH, Predmore Z, et al. Core components for a clinically integrated mHealth app for asthma symptom monitoring. Appl Clin Inform 2017;8(04):1031-1043
22 Couture B, Lilley E, Chang F, et al. Applying user-centered design methods to the development of an mHealth application for use in the hospital setting by patients and care partners. Appl Clin Inform 2018;9(02):302-312

23 Dellifraine JL, Dansky KH. Home-based telehealth: a review and meta-analysis. J Telemed Telecare 2008;14(02):62-66

24 Venkatesh V, Davis F. A theoretical extension of the technology acceptance model: four longitudinal field studies. Manage Sci 2000;46:186-204

25 Davis FD, Bagozzi RP, Warshaw PR. User acceptance of computer technology: a comparison of two theoretical models. Manage Sci 1989;35(08):982-1003

26 Nadri H, Rahimi B, Lotfnezhad Afshar H, Samadbeik M, Garavand A. Factors affecting acceptance of hospital information systems based on extended technology acceptance model: a case study in three paraclinical departments. Appl Clin Inform 2018;9(02): 238-247

27 Chiu TM, Ku BP. Moderating effects of voluntariness on the actual use of electronic health records for allied health professionals. JMIR Med Inform 2015;3(01):e7-e7

28 Downing CE. System usage behavior as a proxy for user satisfaction: an empirical investigation. Inf Manage 1999;35(04): 203-216

29 Campbell DT, Cook TD. Quasi-Experimentation: Design \& Analysis Issues for Field Settings. Chicago: Rand McNally College Publishing Company; 1979

30 Ritzhaupt A, Dawson K, Cavanaugh C. An investigation of factors influencing student use of technology in $\mathrm{K}-12$ classrooms using path analysis. J Educ Comput Res 2012;46:229-254

31 Wright S. Correlation and causation. J Agric Res 1921;20(07): 557-585

$32 \mathrm{Hu}$ Lt, Bentler PM. Cutoff criteria for fit indexes in covariance structure analysis: conventional criteria versus new alternatives. Struct Equ Modeling 1999;6(01):1-55

33 McDonald RP, Ho M-HR. Principles and practice in reporting structural equation analyses. Psychol Methods 2002;7(01):64-82

34 Ketikidis P, Dimitrovski T, Lazuras L, Bath PA. Acceptance of health information technology in health professionals: an application of the revised technology acceptance model. Health Informatics J 2012;18(02):124-134

35 So CF, Chung JW. Telehealth for diabetes self-management in primary healthcare: a systematic review and meta-analysis. J Telemed Telecare 2018;24(05):356-364

36 Mettler T. Post acceptance of electronic medical records: evidence from a longitudinal field study. Paper presented at: The 33rd International Conference on Information Systems; Orlando, USA; 2012

37 Chang CP. The technology acceptance model and its application in a telehealth program for the elderly with chronic illnesses [in Chinese]. Hu Li Za Zhi 2015;62(03):11-16

38 Argaez Ed. Internet World Stats statistics; 2019. Available at: https:// www.internetworldstats.com/stats.htm. Accessed February 3, 2020

39 Bech M, Kristensen MB. Differential response rates in postal and Web-based surveys in older respondents. Surv Res Methods 2009; 3(01):1-6

40 Cook JV, Dickinson HO, Eccles MP. Response rates in postal surveys of healthcare professionals between 1996 and 2005: an observational study. BMC Health Serv Res 2009;9:160

41 Hoyle RH. The structural equation modeling approach: basic concepts and fundamental issues. In: Structural Equation Modeling: Concepts, Issues, and Applications. Thousand Oaks, CA: Sage Publications, Inc; 1995:1-15 